\title{
Stage IB Uterine Corpus Adenosarcoma AJCC v8
}

National Cancer Institute

\section{Source}

National Cancer Institute. Stage IB Uterine Corpus Adenosarcoma A/CC v8. NCI

Thesaurus. Code C139897.

Stage IB includes: T1b, N0, M0. T1 b: Uterine corpus adenosarcoma with tumor invading to less than half of the myometrium. NO: No regional lymph node metastasis. M0: No distant metastasis. (AJCC 8th Ed.) 